\title{
Does an integrated information technology system provide support for community pharmacists undertaking Discharge Medicines Reviews? An exploratory study
}

This article was published in the following Dove Press journal:

Integrated Pharmacy Research and Practice

20 September 2017

Number of times this article has been viewed

\author{
Efthymia Mantzourani' \\ Cheryl MWay² \\ Karen L Hodson' \\ 'College of Biomedical and Life \\ Sciences, Cardiff School of Pharmacy \\ and Pharmaceutical Sciences, Cardiff \\ University, ${ }^{2} \mathrm{NHS}$ Wales Informatics \\ Service, Cardiff, Wales, UK
}

Objective: The aim of this study was to explore the views of community pharmacists participating in the pilot of a secure online platform in Wales, the Choose Pharmacy application (CPA), with particular interest in the electronic Discharge Advice Letters (e-DALs) and online Discharge Medicines Review (DMR) form.

Materials and methods: A qualitative approach with semi-structured interviews was adopted. A gatekeeper from National Health Service Wales Informatics Service identified 35 pharmacies, of the 43 pharmacies where the CPA had been implemented, that had completed at least one DMR, and these were therefore invited to an interview.

Results: A total of 17 pharmacists were interviewed. Overall, the results were positive and CPA and e-DAL were perceived to facilitate continuity of care between care settings. The design and usability were perceived as good as pharmacists could navigate the CPA without problems; many felt this was due to the level of training they had received. Many pharmacists were happy for other services to be included on the platform due to its ease of use and automatic reimbursement. Several pharmacists felt that communication between primary and secondary care can be further improved as the uptake of e-DAL increases.

Conclusion: CPA was found to streamline the completion of online DMR improving continuity of care between primary and secondary sectors, which in turn should improve patient safety on discharge from hospital.

Keywords: continuity of care, electronic Discharge Advice Letter, Discharge Medicines Review

\section{Introduction}

Medication-related information is sometimes incomplete when patients transfer between health care settings such as at hospital admission and hospital discharge, ${ }^{1-3}$ often because of miscommunication between care providers. ${ }^{4,5}$ Inadequate documentation at discharge can negatively impact on the quality of subsequent patient care, ${ }^{2,6-8}$ even leading to rehospitalisation. ${ }^{9,10}$ In addition, concerns have been raised by general practitioners (GPs) regarding the completeness and timeliness of receipt of discharge information..$^{3,11-13}$ The need for community pharmacies to receive discharge information has also been noted. ${ }^{14,15}$

There has been increasing interest worldwide in addressing continuity of care for patients by introducing standards and templates for discharge information, ${ }^{16,17}$ and integrating pharmacists in hospital and post-discharge patient support. ${ }^{18,19}$ Standardized electronic transfer of medication-related issues has been proposed as a way to improve
Correspondence: Karen L Hodson School of Pharmacy and Pharmaceutical Sciences, Cardiff University, King Edward VII Avenue, Cardiff CFIO 3NB, Wales, UK

Email HodsonKL@cardiff.ac.uk 


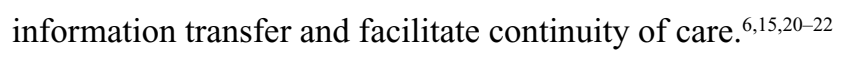
However, there does not seem to be a formal process for the reconciliation of medicines on discharge from hospital, and the role of the community pharmacist in such a process is often overlooked by other health care professionals. ${ }^{3}$

In Wales, the Discharge Medicines Review (DMR) service was established in November 2011 to improve the management of medicines following a patient being discharged from a care setting. ${ }^{23}$ The community pharmacist undertakes the service and receives a fee of $£ 37$ per patient. The service consists of two parts: part one is patient identification and reconciliation of medicines following discharge and part two is designed to support adherence to medication. The community pharmacist undertaking the DMR identifies, records and resolves any differences between the discharge prescription from hospital and the first prescription written by the GP. Examples of such differences may include a medicine being restarted in the community that was discontinued by the hospital, a wrong strength being prescribed or a wrong formulation. These are documented on the DMR form, and once complete the pharmacist inputs the relevant details into a national database to claim payment for the service. Patients are recruited for the service either as a self-referral, by the pharmacy knowing the patient has been in hospital, or by referral from a health care professional. In the DMR evaluation, ${ }^{14} 81 \%$ of DMRs $(n=14,649)$ had at least one difference between the discharge prescription and the first prescription post discharge received by the community pharmacist. The most common difference $(52 \%)$ was a medicine discontinued or restarted. The discrepancy rate was 1.3 per DMR (range 1.10-1.44). While many community pharmacists were supportive of the service, they identified a few barriers to its implementation. These were the difficulty in identifying eligible patients as they were not informed the patient had been in hospital, a lack of access to discharge information and the paperwork not being user-friendly.

Another initiative supported by the government in Wales to strengthen interdisciplinary collaborations and address continuity of care issues was the development by National Health Service Wales Informatics Service (NWIS) of the Medicines Transcribing and electronic Discharge (MTeD) system. MTeD, which was piloted in 2012 and is now being rolled out across Wales, allows hospital pharmacists to update the patient's medication list which is then imported it into a Discharge Advice Letter (DAL), that is then subsequently provided as a hard copy to patients and electronically transferred to the patient's GP on the day of their discharge (Figure S1).
After the DMR evaluation, in April 2015, NWIS developed a pharmacy-specific electronic version of the DAL (e-DAL) that includes information about the patient's medication and any changes that have been made during the patient's hospital stay. ${ }^{24-26}$ If a patient consents, this e-DAL can be accessed from a secure online platform by a pharmacist in a nominated community pharmacy. ${ }^{27}$ The medicines' information in the e-DAL can be imported into a newly developed online DMR form within the platform which was integrated automatically with the process for claiming the DMR fee. In order for the community pharmacist to know information is available to access, since September 2015, the pharmacy receives an email asking them to access the secure platform to view the e-DAL. This platform, which was originally developed in Wales for the Common Ailment Scheme, is called the Choose Pharmacy application (CPA). Training on how to use CPA was undertaken by pharmacists in all pharmacies where CPA had been implemented.

The functionality of the e-DAL, email notification and integration of the e-DAL with the online DMR form was piloted in three health boards across Wales. Before further rollout across Wales, feedback was required to inform its future development. Therefore, the aim of this study was to explore community pharmacists' views on the CPA for the provision of pharmacy services, with particular interest in the e-DALs and online DMR form.

\section{Materials and methods}

A qualitative methodology was adopted to explore the pharmacists' opinions. Figure 1 outlines the main steps in the methodology.

\section{Ethical approval}

The Cardiff School of Pharmacy and Pharmaceutical Science Research and Ethics Committee (SREC) granted full ethical approval (October 2015).

\section{Data collection}

\section{Sampling method, recruitment and consent}

While 43 community pharmacies across three health boards had access to the CPA, information from National Health Service (NHS) Wales Shared Services Partnership (NWSSPPrimary Care Services [PCS]) showed that between April and October 2015, 35 pharmacies were completing DMRs electronically using the CPA. As eight pharmacies had not completed any DMRs, they were excluded from the study.

The gatekeeper from NWIS emailed all the 35 eligible pharmacies. After a follow-up email, all nonresponders were 


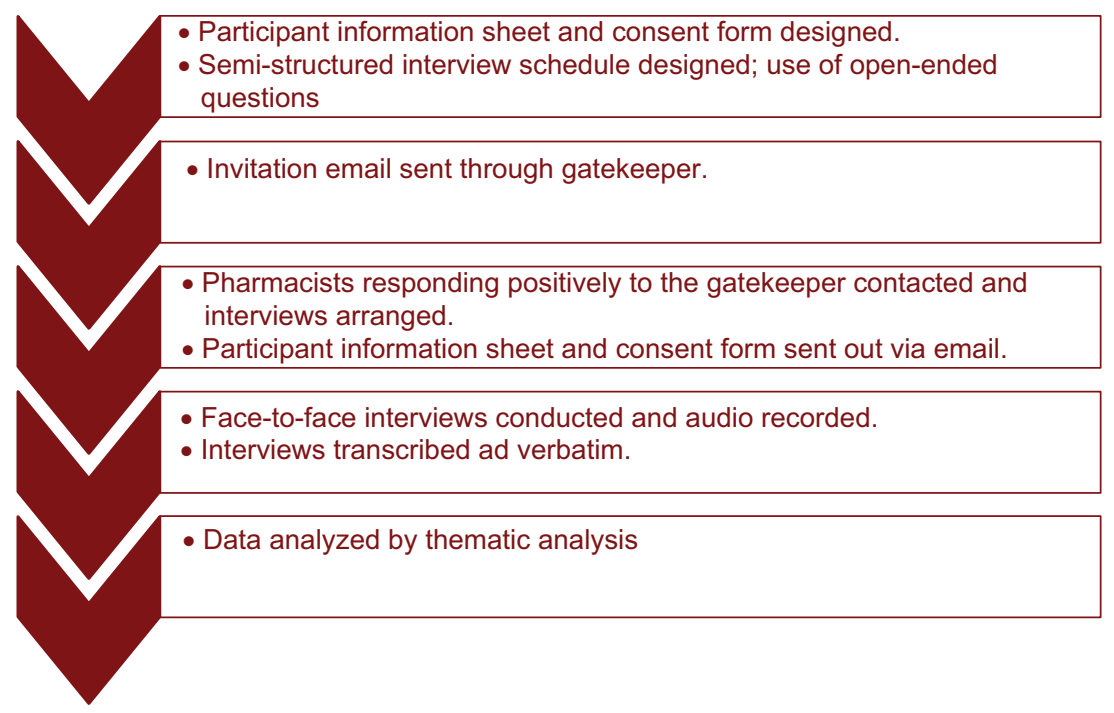

Figure I Methodology overview.

telephoned by the gatekeeper. Due to time restrictions, all pharmacists who agreed to participate were immediately contacted by either of the two researchers at Cardiff University by telephone to arrange an interview. A participant information sheet and consent form were provided via email preceding the interview. This information included reasons for undertaking the research and interviewer characteristics. No follow-up of nonrespondents was completed, and hence reasons for nonparticipation are unknown.

\section{Interviews}

Face-to-face semi-structured interviews were conducted from November 4, 2015, to December 16, 2015, by two female researchers, completing a Masters level project, at a time and location most convenient for the pharmacist. The researchers received training followed by practice interviews prior to commencement of the study. No prior relationship to the participants was present. The interviews were audio recorded using a dictaphone; full informed consent was obtained prior to recording the interview and no one else was present besides the participant and the researcher. No repeat interviews were carried out.

\section{Research instrument tool}

An interview schedule was designed and piloted to minimize bias during the interviews (Figure S2). ${ }^{28}$ There were three main constructs; opinions were explored on CPA in general, on e-DALs and DMRs. The participant was not restricted to these areas, and several open-ended questions were included at the end of the interview to allow the pharmacist to talk more generally.

\section{Data analysis}

The audio recordings were transcribed ad verbatim using SpeechExec software. ${ }^{29}$ Once transcribed, the data were quality assured and anonymized to ensure confidentiality was maintained. Both researchers coded the data independently before combining into coding that was subsequently checked by the wider research team. Inductive thematic analysis was used to identify and analyze themes. ${ }^{30}$

\section{Results}

Responses were received from 21 of the 35 eligible pharmacies. The first 17 pharmacists who responded were interviewed (49\%), due to time constraints. The final sample included pharmacists from the three health boards, with a variety of experience using CPA, and the number of DMRs conducted. Interviews lasted between 20 and 45 minutes and all questions followed the same guide. Table 1 outlines relevant characteristics of pharmacists interviewed as part of the research. Table 2 presents the main themes and a selection of subthemes after thematic analysis of the data, with example quotes for each. The full table with subthemes and representative quotes is included in Table S1.

\section{Uptake of e-DALs}

A total of 14 pharmacists highlighted a lack of e-DAL use in secondary care, either because there were not enough wards using the system or a perception that the system is not being utilized appropriately at ward level. Many pharmacists felt positively about the use of e-DALs in future despite not having received any before the interviews were conducted. 
Table I List of participants interviewed

\begin{tabular}{|c|c|c|c|}
\hline $\begin{array}{l}\text { Participant } \\
\text { code }\end{array}$ & $\begin{array}{l}\text { University } \\
\text { Health } \\
\text { Board* }\end{array}$ & $\begin{array}{l}\text { Number } \\
\text { of e-DAL } \\
\text { received** }\end{array}$ & $\begin{array}{l}\text { Number of DMRs } \\
\text { conducted by } \\
\text { pharmacy using } \\
\text { online form*** }\end{array}$ \\
\hline$\overline{\mathrm{Al}}$ & I & I & 15 \\
\hline $\mathrm{A} 2$ & I & I & 36 \\
\hline A3 & I & 0 & 3 \\
\hline A4 & 2 & 2 & 34 \\
\hline A5 & 2 & 0 & 3 \\
\hline A6 & 1 & I & 3 \\
\hline A7 & 2 & 2 & 30 \\
\hline A8 & 2 & 0 & 36 \\
\hline A9 & 3 & 0 & I \\
\hline AIO & 3 & 10 & 3 \\
\hline All & 3 & 0 & 56 \\
\hline $\mathrm{A} \mid 2$ & 3 & 2 & 20 \\
\hline $\mathrm{A} / 3$ & 3 & I & 8 \\
\hline Al4 & 3 & 0 & 87 \\
\hline Al5 & 3 & 3 & 5 \\
\hline Al6 & 2 & 1 & 6 \\
\hline Al7 & 2 & 26 & 62 \\
\hline
\end{tabular}

Notes: *Each health board has been anonymized. **Number of e-DALs stated in this column refers to the number that the interviewee had access to from the hospitals between the introduction of the scheme in April 2015 and October 2015. ***Number of DMRs stated in this column was obtained from the gatekeeper and refers to the number of DMRs the pharmacy completed using the online form and submitted for payment between the introduction of the scheme in April 2015 and October 2015. A subset of these DMRs was completed using the e-DAL, as detailed in third column of the table.

Abbreviations: DMR, Discharge Medicines Review; e-DAL, electronic Discharge Advice Letter.

Several pharmacists hoped that an increased uptake of e-DAL would be beneficial to both them and their patients.

\section{Information in e-DAL vs. DAL}

Most pharmacists preferred using the e-DAL via the CPA to receiving a paper DAL, stating that previous problems with incomplete information were now obsolete. Several pharmacists liked that all the information was displayed on one, easy to view page. The majority of pharmacists also felt that the e-DAL overcomes transcription errors that were common with paper DALs and liked the fact they could print the e-DAL out.

\section{Usability of the CPA}

Despite the teething issues, and some input procedures perceived as laborious, it was recognized that the system is straightforward to use. It was highlighted that the training provided, even though different between health boards, was pivotal in increasing the pharmacists' confidence in using the system.

\section{Patient confidentiality}

All pharmacists interviewed had no concerns regarding patient confidentiality when sharing data by using the application, and deemed it to be secure. It was also noted that patients did not express any concerns over secondary care sharing their discharge information via CPA, and agreed to provide consent prior to pharmacists accessing their e-DAL.

\section{Impact of electronic DMR (e-DMR) service}

Many pharmacists re-emphasized the importance of the DMR service with some stating it was the most important service they had to offer patients, as they believe it improves patient safety by reducing medication errors.

Most pharmacists believed the electronic version of the DMR to be superior to the paper version. When an electronic copy of the DAL was available, the medication would automatically populate onto the DMR form reducing inputting time and potential for medication errors.

\section{Communication}

Several community pharmacists felt that communication between hospitals, GP surgeries and patients has not improved yet, especially during the patient discharge process. All but one pharmacist believed that communication had not improved between health care practitioners in primary and secondary care. Many pharmacists were only contacted by hospitals if a patient who required a monitored dosage system (MDS) was being discharged.

\section{Expanding the CPA}

Out of 17 pharmacists, 13 believed that additional services should also be made available via the CPA with all services amalgamated on one application; information on the services conducted in community could also be shared with the community pharmacy patient medication record (PMR) and directly with the GP surgeries.

\section{Discussion}

The aim of the study was to explore community pharmacists' opinions on CPA, e-DALs and the online DMR form. Overall, the results were positive. The development of CPA has allowed the safe electronic transfer of medication-related information to community pharmacies; the need for which has been highlighted in the literature. ${ }^{15}$ The pharmacists interviewed in our study perceived the design and usability of CPA as good as pharmacists were able to navigate the application without problems. Many felt this was due to the level of training they had received. The fact that many of the pharmacists were happy for other services to be included on the platform, due to its ease of use and automatic reimbursement, also dem- 
Table 2 Themes, subthemes and representative quotes from the thematic analysis of the data

\begin{tabular}{|c|c|c|}
\hline $\begin{array}{l}\text { Theme } \\
\text { number }\end{array}$ & $\begin{array}{l}\text { Themes and } \\
\text { subthemes }\end{array}$ & Representative quotes \\
\hline \multirow[t]{4}{*}{ I } & Uptake of e-DALs & \\
\hline & $\begin{array}{l}\text { Uptake in } \\
\text { secondary care }\end{array}$ & $\begin{array}{l}\text { "If it could be rolled out onto more wards overtime then it would be much better for us and much better for the } \\
\text { patient." (A6) }\end{array}$ \\
\hline & & "I can just see so much potential if it got rolled out properly." (AI7) \\
\hline & & "The wards that are using it, are they using it to its full advantage?" (A7) \\
\hline \multirow[t]{7}{*}{2} & Information in e-DA & - vs. DAL \\
\hline & Completeness & "There is no chance of any sort of errors happening on the discharge because we are getting the exact \\
\hline & & information, the right dosages, we can look at it, print it out which is much easier [than the DAL].” (A6) \\
\hline & & $\begin{array}{l}\text { "I think (the e-DAL) is much better than what we use to have (DAL) because not only do you get the list of } \\
\text { medication, you get what has stopped, what has changed, what has started so l'm very happy with the quality of } \\
\text { the e-DAL." (AI5) }\end{array}$ \\
\hline & Presentation & $\begin{array}{l}\text { "Again it's so much clearer on the electronic version than it was on the paper version, having to go through all } \\
\text { the pages, it's all there on one page." (AI3) }\end{array}$ \\
\hline & & "you're [sic] avoiding having to try and read doctor's handwriting." (A3) \\
\hline & & "We can look at it, print it out which is much more easier than trying to get hold of the DAL from patients." (A6) \\
\hline \multirow[t]{2}{*}{3} & Usability of the CPA & \\
\hline & Training & $\begin{array}{l}\text { "I had a small training session with the people from the health board and after that I didn't need to refer to the } \\
\text { manual. I didn't need to call them up for any assistance with anything; it was fairly self-explanatory once you got } \\
\text { in and starting using it." (A4) }\end{array}$ \\
\hline \multirow[t]{2}{*}{4} & Patient confidentialit & \\
\hline & Patient consent & $\begin{array}{l}\text { "It's fine, it's well um, we get patients to sign application form and patients are well aware of what they are } \\
\text { signing up for so as far as we are concerned it's really confidential." (A6) }\end{array}$ \\
\hline \multirow[t]{3}{*}{5} & Impact of e-DMR sel & vice \\
\hline & Link to e-DAL & $\begin{array}{l}\text { "It's just so much quicker with the e-DAL because you don't need to write in the medicines because it sort of } \\
\text { does it itself and also it sort of like reduces human error." (AI7) }\end{array}$ \\
\hline & Patient safety & $\begin{array}{l}\text { "Patient safety (important service) because we do see quite a lot of errors or quite a lot of drugs that have been } \\
\text { missed from, dosages that we can pick up so easily which obviously makes continuity of care for the patient } \\
\text { seamless. Yes, so it's one of the most valuable services, simply because we want to stop people going back into } \\
\text { hospital at the end of the day." (A2) }\end{array}$ \\
\hline \multirow[t]{11}{*}{6} & Communication & \\
\hline & Patient & "You know I think it's much better if people are educated to bring their DAL into the pharmacy." (AI2) \\
\hline & Hospital & "No nothing has changed at all [communication]. I mean every single week we've had someone that [sic] have \\
\hline & & realized they only have 3 or 5 days' supply from hospital and they haven't made that arrangement. They don't \\
\hline & & know, it is not explained to them." (AI6) \\
\hline & & "...the hospital will identify them as somebody who has a tray from us they'll always contact us prior to discharge \\
\hline & & $\begin{array}{l}\text { to say 'you've got a tray patient coming out with, there's been } X \text { change to their medication'. They're only } \\
\text { patients they will notify us of." (A4) }\end{array}$ \\
\hline & & "We haven't been getting the e-DALs through but certainly the communication, like I was saying from the \\
\hline & & hospital to us has certainly improved since these trials." (A5) \\
\hline & GP surgery & $\begin{array}{l}\text { "We don't have to go out to the surgery and pull the discharges in, um, even though luckily they do, they play } \\
\text { ball with us no problem." (A2) }\end{array}$ \\
\hline & & $\begin{array}{l}\text { "We rarely see the patient actually bring in the discharge sheets in themselves. It's normally sent from the GPs } \\
\text { and some of the GPs themselves are reluctant to give the information out. (A6) }\end{array}$ \\
\hline \multirow[t]{3}{*}{7} & Expanding the CPA & \\
\hline & & "The more services we can get by the function [CPA] where we can do it straight away there the better." (AI0) \\
\hline & & "l'd like it [services] all through one system, Why make it more complicated?" (AI4) \\
\hline
\end{tabular}

Abbreviations: CPA, Choose Pharmacy application; e-DALs, electronic Discharge Advice Letters; e-DMR, electronic Discharge Medicines Review; GP, general practitioner.

onstrates their support for CPA. While not formally evaluated in this research, the community pharmacists did express that patients did not seem concerned about providing information on their medicines via a secure online platform. The challenge for developing secure online platforms will always be achieving a balance between protecting patient information and at the same time not creating excessive barriers for the pharmacists accessing patient data; the latter was mentioned by some pharmacists in the interviews.

The results demonstrated that the pharmacists felt that the e-DAL had improved the quality and completeness of information provided to them and allowed the DMR process to be more efficient as they no longer were required to manually input medicines into the DMR form. This is encouraging as 
the completeness and timeliness of discharge information is often cited as one of the main issues associated with continuity of care for patients between care settings. ${ }^{3,11-13}$ The MTeD system that generates the e-DAL and the discharge letter to GPs has been designed so that the end user can populate their GP medication record or the DMR form with the medicines and hence prevent any transcription errors. This is important as just having a record of the medicines does not necessarily improve the inclusion of the medicines in the GP record. ${ }^{31}$ Systems need to be developed to help the process to be safe and efficient.

Due to the limited rollout of MTeD within the health boards at the time of this study, the number of e-DALs sent to community pharmacists was relatively low. However, it is encouraging that those community pharmacists who had received an e-DAL agreed that e-DALs were superior to paper-based DALs. These results are in line with previous research by Pocklington and Al-Dahir ${ }^{32}$ who demonstrated that discharge summaries completed electronically have higher completion rates than the paper version, although the level of detail provided is dependent on the practitioner completing the DAL. Their results also showed that the electronic version of the DAL is more likely to be fully completed and sent promptly.

As MTeD is implemented in more hospitals across Wales, the ability for community pharmacists to receive an e-DAL increases. However, this still depends upon the engagement of the hospital pharmacy team referring patients for a DMR. Hodson et $\mathrm{al}^{14}$ in their evaluation of the DMR scheme identified that often it was the patients using an MDS that were referred for a DMR, even though the criteria for a DMR are either patients on four or more medicines, changes in medication, professional judgment or patients using monitored dosage systems (MDS). To help erode the continuity of care issues, pharmacy teams within the hospital sector need to take responsibility for transferring good quality and timely information on a patient's medicines and any changes to their regimen to GPs and community pharmacists. In the study by Redmond et al, ${ }^{3}$ where they asked GPs and community pharmacists their opinions on medication management at transitions of care in Ireland, both the GPs and the community pharmacists were in favor of the hospital pharmacist playing a further role in this area. They also felt that the role of the community pharmacist should be expanded to identify any prescribing errors following transition from one sector to another; this role identified is the role of the community pharmacist plays in the DMR scheme in Wales.

\section{Conclusion}

The development in Wales of the DMR service, e-DAL for community pharmacists and the CPA addresses many of the barriers to continuity of care reported in the literature. ${ }^{3-5,11-13,15}$ The development of a secure online platform that community pharmacists find easy to access and navigate and patients seem to have confidence in allows further developments in this area to be made. There is much interest in the UK in developing the role of the community pharmacist, for them to provide a more clinical service. Governments are acknowledging the importance of pharmacists being granted access to individualized patient records, ${ }^{33,34}$ to help patients and to try to reduce medicines-related readmissions. A platform such as CPA would provide a secure way for this to occur. When developing services to help meet the continuity of care agenda, it is important to include end users of the system in the design and to regularly obtain feedback. From our experience, this has really helped to further develop the systems, so that not only is information transferred electronically to GPs and community pharmacists in a secure way but also it allows them to import the information within the electronic format into their systems easily, meaning that information on patient's medication is up-to-date.

\section{Limitations}

There are a number of limitations to this study. First, the study was designed to only interview those pharmacists who had used the CPA to complete DMRs electronically. Eight pharmacies within the three health boards who had implemented CPA but not completed electronic DMRs were therefore not invited to participate. An interview with them may have been interesting specifically to explore some fundamental barriers in engaging with the system.

The second limitation was the small number of e-DALs that had been sent to the community pharmacies; this may have impacted upon the ability of the interviewees to comment on this development. The small number of e-DALs may be accounted for by the delay in the email notification to community pharmacies "going live" and the rollout of MTeD in each health board, resulting in only a limited number of wards using the application at the time of the study.

Of the 35 pharmacies eligible to be included in the study, 17 participating pharmacists were interviewed. No follow-up of nonrespondents was completed. The fact that not many e-DALs had been sent to community pharmacies may have meant that the pharmacists had little opinion concerning the topic and therefore had no motivation to participate in the research. 
Table 3 Pharmacists' recommendations for improvements

\begin{tabular}{ll}
\hline Improvement & Recommendation \\
\hline Location & $\begin{array}{l}\text { Remove the need to confirm IP address as it is time-consuming and there are other barriers to ensure } \\
\text { patient confidentiality is maintained }\end{array}$ \\
$\begin{array}{ll}\text { Training } & \text { Standardize training so that every pharmacist has same level of training } \\
\text { Additional information on e-DAL } & \text { Ensure that e-DALs contain the same level of details as paper DAL } \\
\text { Print functionality } & \text { Add a print function to enable pharmacists to print the e-DMR if needed } \\
\text { Increase e-DAL accessibility } & \text { Increase the accessibility of e-DAL through additional wards and hospitals } \\
\text { Suggested medication } & \text { A drop-down box of suggested medication similar to that on the PMR should be made available. This will } \\
& \begin{array}{l}\text { reduce the time for pharmacists to type each medication } \\
\text { Insert a functionality which can audit the number of DMRs completed }\end{array} \\
\text { Audit functionality } & \text { Incorporate a functionality whereby pharmacists can re-access DMRs once they have been claimed to } \\
\text { Records } & \text { provide a record of the patient's history } \\
\text { Enhance the CPA to encompass additional services }\end{array}$ \\
\hline
\end{tabular}

Abbreviations: DMR, Discharge Medicines Review; e-DAL, electronic Discharge Advice Letter; e-DMR, electronic DMR; PMR, patient medication record.

While only half of the eligible pharmacists $(\mathrm{n}=17)$ were interviewed due to data gathering having to occur over a 4-week period, no new themes emerged after the 13th interview. Therefore, it may not have been beneficial to complete further interviews. Of those interviewed, there was a selection across the three health boards, and a variety in the number of e-DALs received and DMRs completed. Therefore, we believe that the interviews provided an overview of the opinions and issues regarding the CPA and completion of DMRs.

One further limitation was that some pharmacists who had agreed to be interviewed lacked time to participate in an interview within the private consultation room. The interview was therefore conducted in the dispensary without an audio recording. Notes were taken during and after the interview to ensure the data gathered were accurate. However, some information may have been inadvertently omitted.

\section{Recommendations}

One objective was to determine pharmacists' individual views on what could be improved. The feedback included enhancements that could be made to e-DALs, e-DMRs and to the CPA. From the results gathered, Table 3 represents recommendations made by the pharmacists.

\section{Future work}

MTeD and e-DAL need to be rolled out across Wales so that all wards in the hospitals are using it. This will allow highquality, timely information to be communicated to the patient, GP and community pharmacist, which should result in safer management of medicines at discharge from hospital. As of May 2017, MTeD has been implemented in 156 wards across five health boards, with around 2,000 e-DALs per week being sent to GPs. In April 2017, there were 177 DMRs completed by 47 community pharmacies using the CPA and of these 98 (55\%) were completed using an e-DAL.

While those interviewed were complimentary about CPA and the developments, further qualitative studies should be completed with pharmacists who have not used the system, to identify if there are any barriers to using it and how to ensure maximum engagement with it.

This is particularly important as NWIS has now secured funding from the Welsh Government to roll out the CPA to all community pharmacies in Wales by March 2020. One of the recommendations from this study is for CPA to encompass additional services, so that all services can be accessible through the same application. Currently, NWIS is developing the CPA to provide access to the Welsh GP Record to support the provision of the Emergency Medicines Supply (EMS) service, also to record the supply of emergency hormonal contraception and administration of influenza vaccination. Further services via the CPA are being considered. It is also planned to share appropriate information from CPA electronically with patients' GPs, PMR systems and with hospital-based health care professionals through the Welsh Clinical Portal.

\section{Acknowledgments}

The development of the pharmacy e-DAL, the DMR form within the CPA and the electronic notification to the community pharmacy at discharge were developed by NWIS and funded by the Welsh Government's Health Technology and Telehealth Fund (HTTF). The rollout of CPA across Wales is being funded through the Welsh Government's Efficiency Through Technology Fund (ETTF).

\section{Disclosure}

Mrs Cheryl Way works for the NHS Wales Informatics Service and has led on the development of the CPA. The other authors report no conflicts of interest in this work. 


\section{References}

1. Coleman EA, Min S, Chomiak A, Kramer AM. Posthospital care transitions: patterns, complications, and risk identification. Health Serv Res. 2004;39(5):1449-1466.

2. Kripalani S, LeFevre F, Phillips CO, Williams MV, Basaviah P, Baker DW. Deficits in communication and information transfer between hospital-based and primary care physicians: implications for patient safety and continuity of care. JAMA. 2007;297(8):831-841.

3. Redmond P, Carroll HC, Grimes T, et al. GPs' and community pharmacists' opinions on medication management at transitions of care in Ireland. Fam Pract. 2016;33(2):172-178.

4. Picton C, Wright H. Keeping Patients Safe When They Transfer Between Care Providers - Getting Medicines Right. Final Report. London: Royal Pharmaceutical Society; 2012. Available from: http://www.nhs. uk/news/2011/07July/Documents/Transfer\%20of\%20Care\%20Professional\%20Guidance\%20-\%20FINAL.pdf. Accessed May 8, 2017.

5. Braund R, Coulter CV, Bodington AJ, Giles LM, Greig A, Heaslip LS. Drug related problems identified by community pharmacists on hospital discharge prescriptions in New Zealand. Int J Clin Pharm. 2014;36(3):498-502.

6. Wilson S, Ruscoe W, Chapman M, Miller R. General practitionerhospital communications: a review of discharge summaries. J Qual Clin Pract. 2001;21(4):104-108.

7. McMillan TE, Allan W, Black PN. Accuracy of information on medicines in hospital discharge summaries. Intern Med J. 2006;36(4):221-225.

8. Garrett T, McCormack C. Does an electronic discharge referral system improve the quality of medication prescribing? J Pharm Pract Res. 2014;44(1):29-34.

9. Moore C, Wisnivesky J, Williams S, McGinn T. Medical errors related to discontinuity of care from an inpatient to an outpatient setting. J Gen Intern Med. 2003;18(8):646-651.

10. Boockvar K, Fishman E, Kyriacou CK, Monias A, Gavi S, Cortes T. Adverse events due to discontinuations in drug use and dose changes in patients transferred between acute and long-term care facilities. Arch Intern Med. 2004;164(5):545-550.

11. Care Quality Commission. Managing Patients' Medicines after Discharge from Hospital. 2009. Available from: http://webarchive. nationalarchives.gov.uk/20101201001009/http:/www.cqc.org.uk/_db/_ documents/Managing_patients_medicines_after_discharge_from_hospital.pdf. Accessed May 8, 2017.

12. Karapinar F, van den Bemt PM, Zoer J, Nijpels G, Borgsteede SD. Informational needs of general practitioners regarding discharge medication: content, timing and pharmacotherapeutic advice. Pharm World Sci. 2010;32(2):172-178.

13. Mahfouz C, Bonney A, Mullan J, Rich W. An Australian discharge summary quality assessment tool: a pilot study. Aust Fam Physician. 2017;46(1-2):57-63.

14. Hodson K, Blenkinsopp A, Cohen D, et al [webpage on the Internet]. Evaluation of the Discharge Medicines Review Service; 2014. Available from: http://www.cpwales.org.uk/Contract-support-and-IT/AdvancedServices/Discharge-Medicines-Review-(DMR)/Evaluation-of-the-DMRService/Evaluation-of-the-DMR-service.aspx. Accessed May 8, 2017.

15. Ensing HT, Koster ES, van Berkel PI, van Dooren AA, Bouvey ML. Problems with continuity of care identified by community pharmacists post-discharge. J Clin Pharm Ther. 2017;42(2):170-177.

16. Scottish Intercollegiate Guidelines Network (SIGN). The SIGN Discharge Document. 2012. Available from: http://www.sign.ac.uk/pdf/ sign128.pdf. Accessed May 8, 2017.
17. Health \& Social Care Joint Unit and Change Agents Team. Discharge from Hospital: Pathway, Process and Practice. London: Department of Health; 2003.

18. Royal Pharmaceutical Society (RPS) [webpage on the Internet]. Keeping Patients Safe When They Transfer between Care Providers - Getting the Medicines Right; 2012. Available from: https://www.rpharms.com/ resources/reports/getting-the-medicines-right?Search=getting $\% 20$ medicines\%20right. Accessed May 8, 2017.

19. Mekonnen AB, McLachlan AJ, Brien JA. Pharmacy-led medication reconciliation programmes at hospital transitions: a systematic review and meta-analysis. J Clin Pharm Ther. 2016;41(2):128-144.

20. van Walraven C, Seth R, Laupacis A. Dissemination of discharge summaries. Can Fam Physician. 2002;48:737-742.

21. National Institute for Health and Care Excellence (NICE) [webpage on the Internet]. Medicines Optimisation: The Safe and Effective Use of Medicines to Enable the Best Possible Outcomes; 2015. Available from: https://www.nice.org.uk/guidance/ng5. Accessed May 8, 2017.

22. Uitvlugt EB, Siegert CEH, Janssen MJA, Nijpels G, Karapinar-Carkit F. Completeness of medication-related information in discharge letters and post-discharge general practitioner overviews. Int J Clin Pharm. 2015;37(6):1206-1212.

23. Andalo D. Discharge medicines review in Wales. Pharm J. 2011;287:530.

24. Mantzourani ED, Leggett $H$, Hodson $K$, Way C. Information required by community pharmacists to complete a Discharge Medicine Review for patients when they are discharged from hospital. Int J Pharm Pract. 2014;22(S2):7.

25. Way, $\mathrm{C}$ [webpage on the Internet]. One System for Health - Update. All Wales Medicine Strategy Group. NHS Wales Informatics Service; 2015. Available from: http://www.awmsg.org/awmsgonline/app/sites earch;jsessionid=77c0ef4bc82508f26299dbe9e579? execution=e1s 1 . Accessed May 8, 2017.

26. Mantzourani E, Hodson K, Hughes L, Way C. Electronic discharge advice letters for community pharmacists. Clin Pharm. 2016;8(1):9. doi: 10.1211/CP.2016.20200228.

27. Malson $\mathrm{G}$. Community pharmacy discharge medicine review service to continue. Pharm J. 2014;292(7808):458.

28. Babbie E. The Practice of Social Research. 14th ed. Canada: Cengage Learning; 2014.

29. Smith F. Research Methods in Pharmacy Practice. London: Pharmaceutical Press; 2002.

30. Brawn V, Clarke V. Using thematic analysis in psychology. Qual Res Psychol. 2006;3(2):77-101.

31. Lefeber GJ, Drenth-va Maanen AC, Wilting I, Jansen PA, van Marum RJ, Egberts TC. Effect of a transitional pharmaceutical care intervention at hospital discharge on registration of changes in medication regimes in primary care. J Am Geriatr Soc. 2014;62(3):565-567.

32. Pocklington $\mathrm{C}, \mathrm{Al}$-Dhahir L. A comparison of methods of producing a discharge summary: handwritten vs. electronic documentation. $B r J$ Med Pract. 2011;4(3):a432.

33. Royal Pharmaceutical Society (RPS) England. Professional Position Statement: Access to Patient Health Record (England). 2013. Available from: https://www.rpharms.com/Portals/0/RPS\%20document $\% 20$ library/Open \%20access/Policy\%20statements/patient-health-record. pdf?ver=2016-10-20-145015-660. Accessed May 8, 2017.

34. Scotland's plans for online patient records will open up access for pharmacists. Pharm J. 2014;292(7801):282. 


\section{Supplementary materials}

\section{Pharmacy Discharge Advice Letter}

Patient:

DOB: 14-Feb-2013 Gender: M

Hospital Number: H7565264 NHS Number:

\begin{tabular}{l}
\hline GP details \\
GP Name \\
Organisation ID \\
GP Address \\
GP Telephone Number \\
\hline
\end{tabular}

Patient details

Patient Name

known As

Date of birth

Gender

NHS Number

Hospital Number

Patient Address

\section{Discharge details}

Date of discharge

21-Mar-2017

Time of discharge

$16: 43$

Discharging consultant

Mr AA Gadgil

Ward

GGH - Dewi Ward

\section{Admission details}

Time of admission

Emergency - GP

Hospital Site

Glangwili General Hospital

\section{Allergies, intolerances and other risks}

Allergies

Allergies Not Recorded

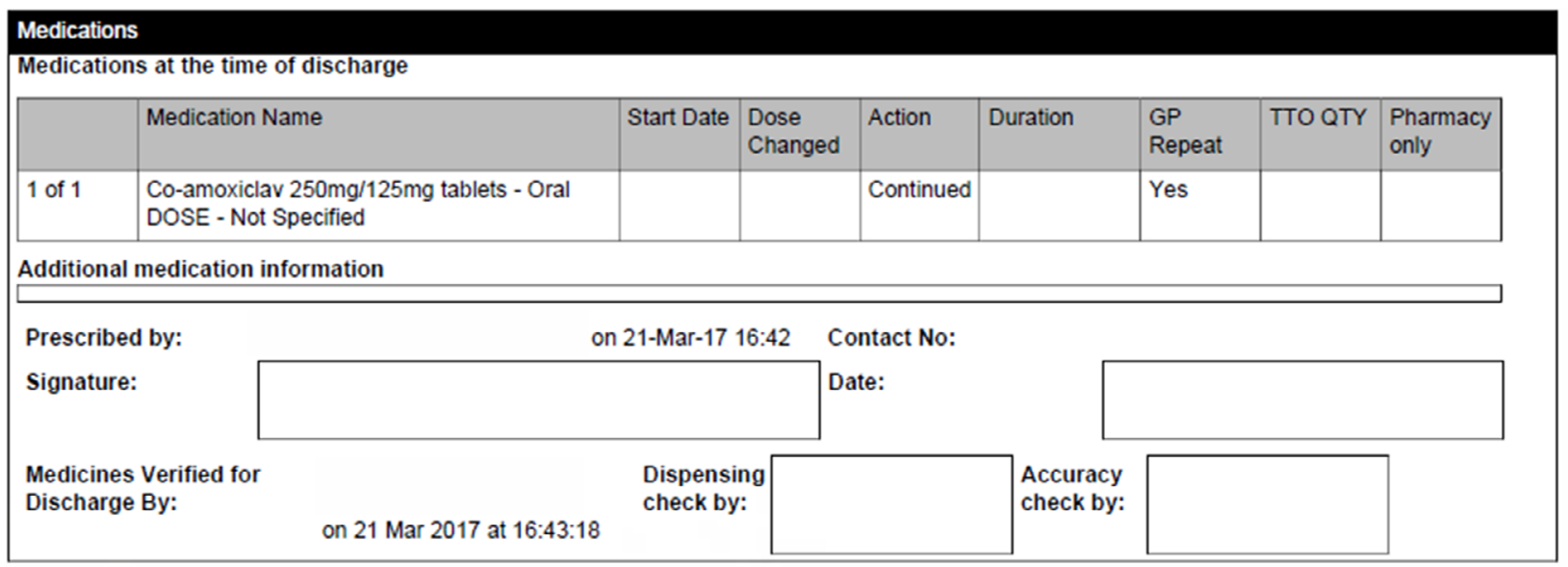

Figure SI Example of an e-DAL.

Abbreviation: e-DAL, electronic Discharge Advice Letter. 
Interview schedule

Opening

Date: Time:

Face-to-face/phone interview

Interview length:

Introduction: Thank you for taking part in this study. I can assure you that the information provided will remain confidential. I would like your permission to audio record this interview; this is to have an accurate set of data your response and opinions.

If you don't have any further questions, I would like to briefly remind you of the purpose of this research as outlined in the information sheet you received previously. Only a few pharmacists have tested out the CPA, and before using it throughout Wales this application needs to be evaluated. We are interested in evaluating this pilot, regarding feasibility and usefulness of e-DALs and the online DMR form.

I would like to ask you some questions to help us reflect on the good and the not so good points of the application, and allow us to improve its quality.

The interview should take about 20-30 minutes.

\section{What do you think about the CPA?}

What about the design?

What about the usability?

Has the application helped you or hindered you? Could you please explain your answer?

What do you think about the patient confidentiality with this application?

Which additional services would you like to see made available in the application?

So, to sum up, for you the application is ........., am I right?

Now let's talk about the e-DAL.

2. What do you think about the e-DAL provided via the application?

What about the quality of the e-DAL?

How would you compare the e-DAL with the paper version

Moving on to the DMR.

3. What can you tell me about the DMRs you conducted with the application?

What about the time spent to complete the DMR?

How would you compare the DMRs you conducted with and without the application?

4. Overall

You have discussed a lot of positive and not so positive aspects of the application, what are the main thoughts you are left with?

\section{Content-mining questions: probes}

\begin{tabular}{|l|l|l|l|}
\hline Probe & Question \\
\hline Amplificatory & Can you tell me more about...? & Can you give me an example of & What exactly do you mean by \\
\hline Exploratory & How does that make you feel & Why do you think it is important to & Does that help you in any way \\
\hline Explanation & What makes you say that & $\begin{array}{l}\text { What was/is about...that made you } \\
\text { feel like }\end{array}$ & \\
\hline Clarification & $\begin{array}{l}\text { Could you explain what you } \\
\text { mean by }\end{array}$ & In what way do you mean that & \\
\hline
\end{tabular}

\section{Closure}

I. Thank you we have covered a lot today, but do you think there is anything that we have missed out?

2. Do you have any further comments about what we have discussed or about the research in general?

3. If you have any further questions or would like more information about the study the contact details are on the information sheet. Thank you.

Figure S2 Exploring pharmacists' views on the integration and use of e-DAL within the community pharmacy setting.

Abbreviations: CPA, Choose Pharmacy application; DMR, Discharge Medicines Review; e-DAL, electronic Discharge Advice Letter. 
Table SI The full list of themes, subthemes and representative quotes from the thematic analysis of the data

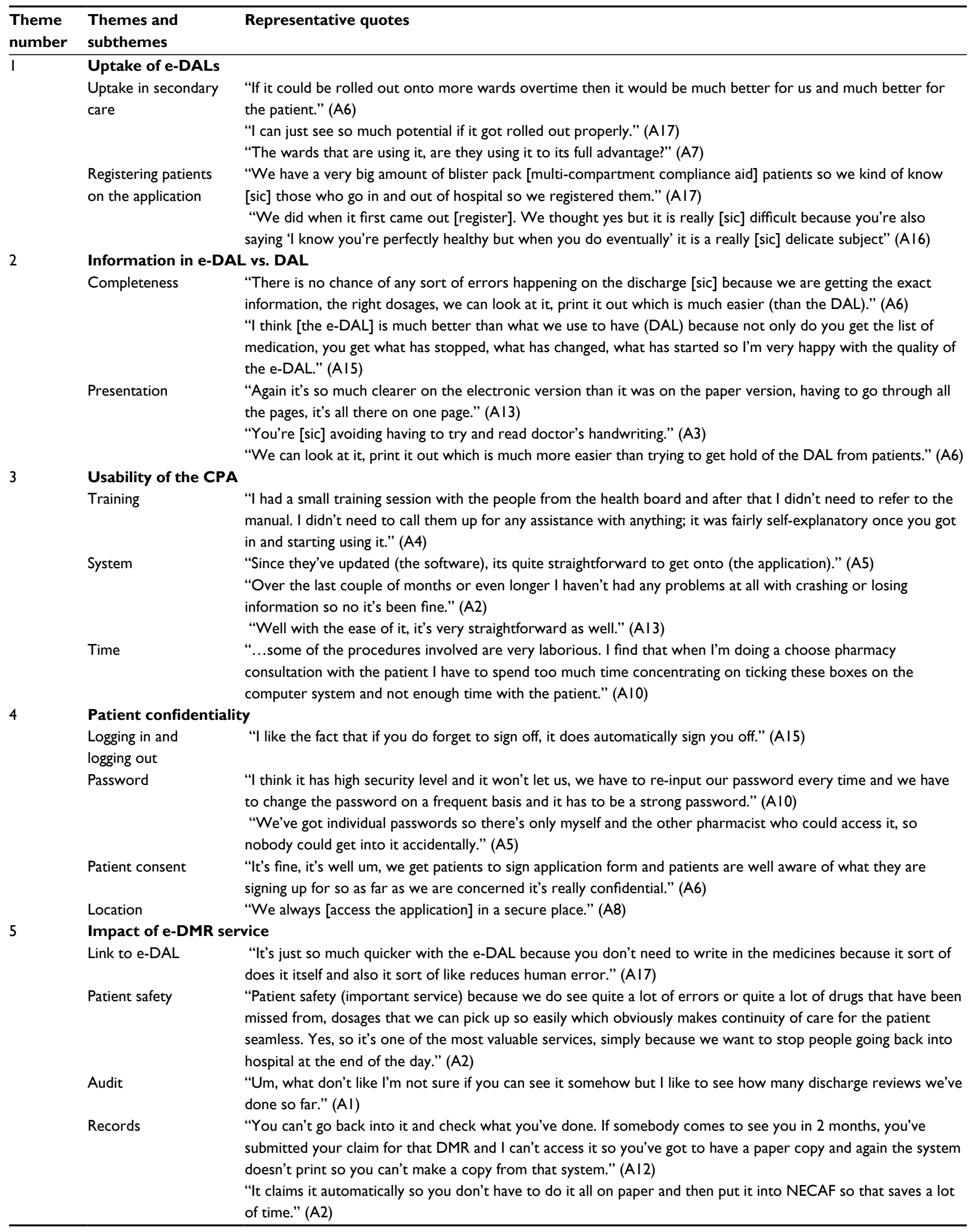


Table SI (Continued)

\begin{tabular}{|c|c|c|}
\hline $\begin{array}{l}\text { Theme } \\
\text { number }\end{array}$ & $\begin{array}{l}\text { Themes and } \\
\text { subthemes }\end{array}$ & Representative quotess \\
\hline \multirow[t]{13}{*}{6} & Communication & \\
\hline & Patient & "You know I think it's much better if people are educated to bring their DAL into the pharmacy.” (AI2) \\
\hline & Hospital & "No nothing has changed at all [communication]. I mean every single week we've had someone that [sic] have \\
\hline & & realized they only have 3 or 5 days' supply from hospital and they haven't made that arrangement. They don't \\
\hline & & know, it is not explained to them." (AI6) \\
\hline & & “ ...the hospital will identify them as somebody who has a tray from us they'll always contact us prior to \\
\hline & & discharge to say 'you've got a tray patient coming out with, there's been X change to their medication'. They're \\
\hline & & only patients they will notify us of." (A4) \\
\hline & & "We haven't been getting the e-DALs through but certainly the communication, like I was saying from the \\
\hline & & hospital to us has certainly improved since these trials." (A5) \\
\hline & GP surgery & $\begin{array}{l}\text { "We don't have to go out to the surgery and pull the discharges in, um, even though luckily they do, they play } \\
\text { ball with us no problem." (A2) }\end{array}$ \\
\hline & & "We rarely see the patient actually bring in the discharge sheets in themselves. It's normally sent from the GPs \\
\hline & & and some of the GPs themselves are reluctant to give the information out. (A6) \\
\hline \multirow[t]{8}{*}{7} & Expanding the CPA & \\
\hline & & "If you see a pattern and the GP or practice nurse can see a pattern, they can ask the question of has this \\
\hline & & patient been referred for a sexual health check, as the information will be there (on the portal).” (AI3) \\
\hline & & "I can't see why [the EHC service] can't be on the system as well so the GPs are aware of how often our \\
\hline & & patients are using things like the EHC." (AI3) \\
\hline & & "The more services we can get by the function [CPA] where we can do it straight away there the better." (AI0) \\
\hline & & “l’d like it [services] all through one system, Why make it more complicated?" (AI4) \\
\hline & & "I'm quite happy the way that other services are recorded at the moment." (AI) \\
\hline
\end{tabular}

Abbreviations: CPA, Choose Pharmacy application; DAL, Discharge Advice Letter; e-DALs, DALs; e-DMR, electronic Discharge Medicines Review; EHC, emergency hormonal contraception; GP, general practitioner; NECAF, National Electronic Claim and Audit Forms.

\section{Publish your work in this journal}

Integrated Pharmacy Research and Practice is an international, peer-reviewed, open access, online journal, publishing original research, reports, reviews and commentaries on all areas of academic and professional pharmacy practice. This journal aims to represent the academic output of pharmacists and pharmacy practice with particular focus on integrated care. All papers are carefully peer reviewed to ensure the highest standards as well as ensuring that we are informing and stimulating pharmaceutical professionals. The manuscript management system is completely online and includes a very quick and fair peer-review system, which is all easy to use. Visit http://www.dovepress.com/ testimonials.php to read real quotes from published authors. 